\title{
Epidemiology of hip fracture and the development of a FRAX model for Uzbekistan
}

\author{
O Lesnyak ${ }^{1} \cdot$ S Ismailov ${ }^{2} \cdot$ M Shakirova ${ }^{2} \cdot$ N Alikhanova $^{2} \cdot$ A Zakroyeva $^{3} \cdot$ L Abboskhujaeva $^{2} \cdot$ H Johansson $^{4}$. \\ NC Harvey ${ }^{5}$ E McCloskey ${ }^{6}$ JA Kanis ${ }^{4,6}$
}

Received: 22 May 2020 / Accepted: 21 July 2020 / Published online: 29 July 2020

(C) The Author(s) 2020

\begin{abstract}
Summary A prospective population-based survey in a region of the Republic of Uzbekistan determined the incidence of fractures at the hip. The hip fracture rates were used to create a FRAX® model to facilitate fracture risk assessment in Uzbekistan.

Objective This paper describes the epidemiology of hip fracture in the Republic of Uzbekistan that was used to develop a country-specific FRAX® tool for fracture prediction.

Methods During a 1-year (2016/17) prospective population-based survey in the Pap district of the Republic of Uzbekistan, hip fractures were prospectively identified from hospital registers, trauma centres and primary care and community sources. Age- and sex-specific incidence of hip fracture and national mortality rates were incorporated into a FRAX model for Uzbekistan. Fracture probabilities were compared with those from neighbouring Kazakhstan and Kyrgystan.

Results Approximately $41 \%$ of hip fracture cases did not come to medical attention, and two thirds of patients overall were not admitted to hospital. The incidence of hip fracture applied nationally suggested that the estimated number of hip fractures nationwide in persons over the age of 50 years for 2015 was 16,764 and is predicted to increase more than three-fold to 60,272 in 2050. FRAX-based probabilities were higher in Uzbekistan than Kazakhstan or Kyrgystan.

Conclusion The FRAX model should enhance accuracy of determining fracture probability among the Uzbek population and help guide decisions about treatment.
\end{abstract}

Keywords FRAX $\cdot$ Fracture probability $\cdot$ Osteoporosis epidemiology $\cdot$ Hip fracture $\cdot$ Uzbekistan

JA Kanis

w.j.pontefract@sheffield.ac.uk

1 Mechnikov North West State Medical University, St. Petersburg, Russia

2 Republican Medical Center for Endocrinology, Tashkent, Uzbekistan

3 Ural State Medical University, 3 Repina street, Yekaterinburg, Russia

4 Mary McKillop Institute for Health Research, Australian Catholic University, Melbourne, Australia

5 MRC Lifecourse Epidemiology Unit, University of Southampton, Southampton, UK

6 Centre for Metabolic Bone Diseases, University of Sheffield, Sheffield, UK

\section{Introduction}

Osteoporosis is a common, chronic and costly condition; its principal clinical consequence is fracture. In Europe, the annual cost of fractures associated with osteoporosis exceeded $€$ 37 billion in 2010 [1]; disability due to osteoporosis was greater than that caused by any single cancer, with the exception of lung cancer, and was comparable or greater than that lost to a variety of chronic noncommunicable diseases, such as rheumatoid arthritis, asthma and high blood pressure-related heart disease $[2,3]$. Fortunately, a wide variety of treatments is available that favourably affect bone mass and thereby decrease the risk of fractures associated with osteoporosis [4]. The use of such interventions by health care practitioners is assisted by instruments that assess patients' fracture risk to optimize clinical decisions about prevention and treatment. The most widely used web-based tool FRAX ${ }^{\circledR}$ (https:// www.sheffield.ac.uk/FRAX/) meets these requirements and computes the 10-year probability of fragility fractures based 
on several common clinical risk factors and, optionally a DXA scan result $[5,6]$. FRAX models are available for 66 countries in 2020 covering more than $80 \%$ of the world population at risk [7] and have been incorporated into more than 100 guidelines worldwide [8].

The availability of FRAX has stimulated studies that can be used for the generation of new FRAX models. Specific examples include Brazil, Mexico and Turkey [9]. The present study is a component part of the Multicenter Multinational population-based Study in Eurasian Countries (EVA study or ЭBA, in Russian). The broad aim of the study was to provide epidemiological information on fracture risk so that FRAX models could be created for Russia [10], Armenia [11], Belarus [12], Moldova [13], Kazakhstan [14], Kyrgyzstan [15] and Uzbekistan. The present report describes the epidemiology of fractures at the hip in Uzbekistan and the generation of a country-specific FRAX model.

\section{Methods}

The republic of Uzbekistan is a landlocked country in turn bordered by five landlocked countries: Kazakhstan, Kyrgyzstan, Tajikistan, Afghanistan and Turkmenistan. Uzbekistan has an area of 447,400 $\mathrm{km}^{2}\left(172,700\right.$ mile $\left.^{2}\right)$ with a population estimated at 33.5 million in 2020 [16]. Uzbeks comprise a majority $(80 \%)$ of the total population. Other ethnic groups include Russians 2\%, Tajiks 5\%, Kazakhs 3\%, Karakalpaks $2.5 \%$ and Tatars $1.5 \%$ (1996 estimates).

The Pap district of Uzbekistan was selected as the catchment area to document the incidence of hip fracture. The district was chosen for its geographic location: in the North and in South-west, the Pap district borders with the Republics of Kyrgyzstan and Tajikistan. In the North-West, the district borders with the Tashkent region, but it is only possible to get access through the mountain pass to Namangan by car for $8 \mathrm{~h}$ of the day. In the South, the Pap region borders the Ferghana region, but patients from neighbouring districts can get medical care there only for a payment. These characteristics were expected to optimize the delineation of a catchment area and minimize the probability that hip fracture patients would be treated outside the region.

The population at risk (that is the total population of the Pap region) proved difficult to determine in that three sources of data were identified that gave very disparate estimates. According to State Department of Statistics [17], the population comprised 193,267 residents in the year of study, of whom 55,098 (29\%) were 40 years of age or older. By contrast, the Pap region Department of Health care estimated the population age 40 years or older at 103,481 [Nematjon Kirgizbayev (2015) Personal Communication to Said Ismailov, 09 September 2015]. Finally, an intermediate estimate of 69,384 was derived from information that individuals age 40 years or more in the Pap district comprised $0.8 \%$ of the total Uzbek population and that the age and sex distribution in Pap was very similar to that in the whole country [18]. We discarded the first two estimates since the apparent incidence of hip fracture derived there from was the lowest and highest worldwide, respectively.

Thus, the catchment population comprised 69,384 residents $(32,784$ men and 36,600 women) age 40 years or older representing $0.8 \%$ of the population of Uzbekistan. The ethnic admixture of the Pap region is similar to that of Uzbekistan. The national population demography by sex and 5-year intervals was obtained from United Nations [16].

The prospective study, undertaken for 1 year from April 2016 until March 2017, was preceded by a training period following a directive from the Uzbekistan Ministry of Health to all medical units of Pap District with the requirement to improve the detection of osteoporotic fractures. A meeting and short training course was organized thereafter for all medical staff of the Pap region who dealt with trauma patients. This included all 27 general practitioners, radiologists, coroners, emergency physicians, traumatologists, surgeons and internists from the district. The aim of the meeting was to improve the recording and documentation of cases of hip fracture in order to develop a national FRAX model. Case report forms were developed to record the patient's age, sex, place of residence, date, character of injury and ICD-10 code (S72.0, S72.1, S72.2). In addition, the official medical records of hip fractures in men and women from the central city hospital registers, the outpatient trauma unit data, GP data and all emergency service data and coroner cases were reviewed. We also looked for the patients from Pap district who were operated in the central hospital of the neighbouring Namangan region (no eligible cases were identified).

We also engaged home visiting nurses who were instructed to notify the traumatologists about each suspected case that had not been referred for hospital care. An orthopaedic surgeon subsequently examined all such cases. The diagnosis was verified clinically (all patients) and where possible, by radiographic examination (89\% of cases). Additionally, we contacted the seven folk healers (tabibs) in the region who were asked to redirect all suspected patients to the Central hospital trauma centre of Pap district. Finally, we contacted the elders of the administrative communities (Mahalla) each covering about 1350-1500 residents. They identified housebound individuals who were subsequently visited at home by the district nurse.

The reason for accessing multiple sources of information including that from primary care was to identify patients with hip fracture who were not admitted to hospital. This strategy was necessary since many patients in Eastern Europe are not hospitalized because facilities for surgical management are limited so that hospital admission is not feasible. In Belarus, for example, $29 \%$ hip fracture cases did not come to hospital 
attention [12]. High rates of non-admittance have been reported in Armenia (44\%) [11], Pervouralsk in Russia (27\%) [10], Georgia (75\%) [19], Kazakhstan (29\%) [14] and Kyrgyzstan $(50 \%)$ [15]. These missing cases from hospital discharge data reinforce a view that data on hip fracture based solely from hospital records are unreliable in this region of the world.

To avoid double counting, further admissions for the same fracture site in the observation time were excluded. In some documents, the fracture ICD-10 code was not specified. In such cases, radiographs were retrieved and fractures, if verified, were included in the database. Permanent residence in the region was a criterion for inclusion. High energy fractures were excluded (falls from greater than from a standing height). We excluded pathological fractures attributable to cancer with metastases or to multiple myeloma.

The age- and sex-specific incidence in 2016/2017 was applied to the population in 2015 to estimate the number of hip fractures nationwide. Additionally, future projections were estimated up to 2050 assuming that the age- and sex-specific incidence remained stable. Population demography was taken from the United Nations using the medium variant for fertility [20].

The data on hip fracture were used to construct the FRAX model. For other major osteoporotic fractures (clinical spine, forearm and humeral fractures), it was assumed that the ageand sex-specific ratios of these fractures to hip fracture risk found in Sweden were comparable to those in Kazakhstan. This assumption has been used for many of the FRAX models with incomplete epidemiological information. Available information suggests that the age- and sex-stratified pattern of fracture is very similar in the Western world, Australia and Eastern Europe [13, 21-23].

The development and validation of FRAX have been extensively described $[5,6]$. The risk factors used were based on a systematic set of meta-analyses of population-based cohorts worldwide and validated in independent cohorts with over 1 million patient-years of follow-up. The construct of the FRAX model for Uzbekistan retained the beta coefficients of the risk factors in the original FRAX model with the incidence rates of hip fracture and mortality rates for Uzbekistan. National mortality rates used data from the World Health Organization for 2014 [24]. Ten-year fracture probabilities were compared to those of the neighbouring countries where a FRAX model was available (Kazakhstan and Kyrgyzstan).

In order to compare hip fracture probabilities with those of other regions of the world, the remaining lifetime probability of hip fracture from the age of 50 years was calculated for men and women, as described previously [25]. In the present analysis, values for Uzbekistan were compared with those of China (Hong Kong), Bulgaria, Canada, Denmark, Finland, France, Greece, Hungary, Kazakhstan, Kyrgyzstan, Mexico, Moldova, Poland, Portugal, Romania, Russia, Spain,
Sweden, Turkey, Ukraine, United Kingdom and the United States (Caucasian) [13, 14, 26, 27].

\section{Results}

Over the period of 1 year, 140 low energy hip fractures were identified in men $(n=52)$ and women $(n=88)$ age 40 years or more. Of these cases, only $47(33 \%)$ of hip fracture patients were hospitalized (Fig. 1). The hospitalized patients were treated with osteosynthesis or conservatively; only two patients underwent emergency hemiarthroplasty surgery.

Twenty-six percent of patients received only outpatient treatment by a traumatologist. The primary care physicians identified $29 \%$ of new hip fracture cases that were managed only in primary care. The home visiting nurses, tabibs and the Community Elders found 15 additional, otherwise unreported cases $(11 \%)$.

The crude annual incidence of low-energy hip fracture in individuals age 40 years or more was 240/100,000 in women and 159/100,000 in men (female/male ratio=1.6). Hip fracture incidence increased with the age up to the age of 90 years in both men and women (Table 1). The incidence in women rose more steeply with age than in men.

\section{Fracture projections}

Assuming that the fracture rates in the Pap district were representative for the whole country, and based on the UN estimates of the Uzbek population for 2015 (31.3 million), the annual number of hip fractures in men and women age 50 years or older in Uzbekistan in 2015 was estimated at 16,764 . The number of hip fractures is expected to increase progressively over calendar year with a greater than three-fold increase by 2050 (Table 2). A similar increase was noted for major osteoporotic fractures.

The 10-year probability of major osteoporotic fracture and hip fracture in Uzbekistan, Kazakhstan and Kyrgyzstan is shown in Fig. 2 in women with a prior fracture by age. Tenyear probabilities in Uzbekistan were consistently, though moderately, higher than in Kazakhstan or Kyrgyzstan.

Lifetime probabilities for hip fracture are shown in Table 3.

\section{Discussion}

This study documented the incidence of hip fracture in the Pap district of Uzbekistan. As expected, hip fractures were more frequent in women than in men. In both sexes, the incidence increased with age. Assuming that the regional incidence was similar to the national incidence, Uzbekistan belongs to the moderate-risk countries for hip fracture for men and women [26]. 
Fig. 1 Proportion (\%) of hip fracture cases admitted to hospital as an inpatient (inpatient), outpatient only at hospital (outpatient), treated only in primary care, identified through the coroner and identified by nurses, tabibs and community elders (other)

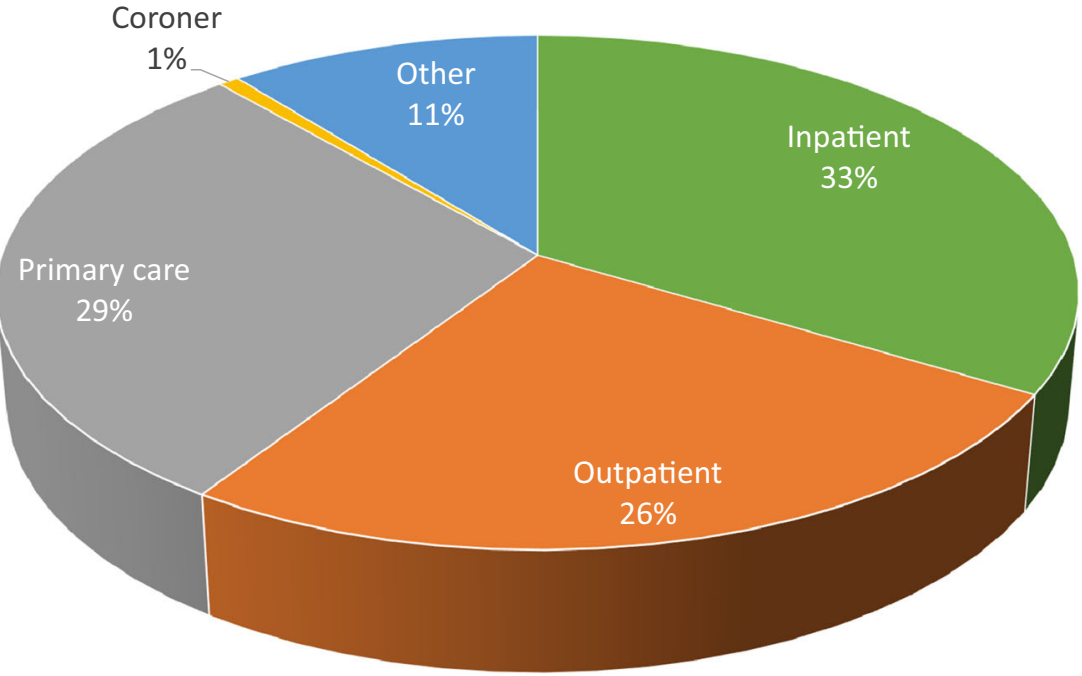

The number of hip fractures nationwide was estimated at 16,764 in 2015.

Demographic projections indicate that fracture burden is due to increase markedly in the future. It is estimated that the annual number of hip and other major osteoporotic fractures will increase more than three-fold over 35 years. The prediction is relatively robust in that all individuals who will be aged 50 years or more in 2050 are currently adults. However, these estimates may be conservative since they assume that the age- and sexspecific risk of hip fracture remains unchanged over this period. If the age- and sex-specific incidence of hip fracture increases, as has been registered in several countries [28], then the number of fractures may be more than doubled. Such projections are important for healthcare planning.
The access to all medical records in this study, including those from primary care, permitted the identification of patients with hip fracture who were not admitted to hospital. The reason for this strategy was the observation that many patients in Eastern Europe are not hospitalized because facilities for surgical management are limited so that hospital admission is not feasible $[10-12,14,19]$. The present study indicated that two thirds of hip fracture cases were not admitted to hospital. The treatment gap arises for many reasons including a lack of emergency orthopaedic surgeons. These findings are also important for healthcare planning and emphasize the importance of exploring care pathways in the design of epidemiological studies.

A minority of countries that have a FRAX model also have robust information on the risk of other major osteoporotic fractures. In the absence of such information, FRAX models
Table 1 Population at risk (2015), number of hip fractures (2016/2017) and annual hip fracture incidence (per 100,000) with $95 \%$ confidence intervals in the male (M) and female (F) population of the Pap district of Uzbekistan

\begin{tabular}{|c|c|c|c|c|c|c|c|c|}
\hline \multirow[t]{2}{*}{ Age (years) } & \multicolumn{2}{|c|}{ Population } & \multicolumn{2}{|c|}{$\begin{array}{l}\text { Number of hip } \\
\text { fractures }\end{array}$} & \multicolumn{2}{|l|}{ M } & \multicolumn{2}{|l|}{$\mathrm{F}$} \\
\hline & M & F & M & F & Incidence & $95 \% \mathrm{CI}$ & Incidence & $95 \% \mathrm{CI}$ \\
\hline $40-44$ & 7480 & 7760 & 2 & 1 & 27 & $3-97$ & 13 & $0.3-72$ \\
\hline $45-49$ & 6312 & 6768 & 3 & 4 & 48 & $10-139$ & 59 & $16-151$ \\
\hline $50-54$ & 5984 & 6632 & 2 & 4 & 33 & $4-121$ & 60 & $16-155$ \\
\hline 55-59 & 4984 & 5536 & 5 & 8 & 100 & $32-234$ & 145 & $62-285$ \\
\hline $60-64$ & 3552 & 3968 & 6 & 7 & 169 & $62-368$ & 176 & $71-364$ \\
\hline $65-69$ & 1704 & 2064 & 8 & 13 & 470 & $203-925$ & 630 & $335-1078$ \\
\hline $70-74$ & 1104 & 1344 & 6 & 9 & 544 & 199-1183 & 670 & $306-1272$ \\
\hline $75-79$ & 912 & 1208 & 7 & 12 & 768 & 309-1582 & 993 & $513-1736$ \\
\hline $80-84$ & 480 & 752 & 7 & 13 & 1458 & $586-3005$ & 1729 & 919-2958 \\
\hline $85-89$ & 216 & 400 & 5 & 11 & 2315 & $748-5406$ & 2750 & $1371-4922$ \\
\hline \multirow[t]{2}{*}{$90+$} & 56 & 168 & 1 & 6 & 1786 & $36-9964$ & 3571 & $1310-7774$ \\
\hline & 32,784 & 36,600 & 52 & 88 & & & & \\
\hline
\end{tabular}


Table 2 Estimated total number of hip and major osteoporotic fractures (MOF) in men and in women age 50 years or older in 2015 projected up to 2050 in Uzbekistan

\begin{tabular}{lrrrrr}
\hline & 2015 & 2020 & 2030 & 2040 & 2050 \\
\hline Hip fracture & & & & & \\
Men & 5942 & 7131 & 10,277 & 15,063 & 20,761 \\
Women & 10,822 & 12,773 & 18,522 & 27,978 & 39,511 \\
Men and women & 16,764 & 19,904 & 28,799 & 43,041 & 60,272 \\
MOF & & & & & \\
Men & 19,262 & 22,846 & 32,182 & 45,245 & 59,383 \\
Women & 41,751 & 49,769 & 71,722 & 102,031 & 133,949 \\
Men and women & 61,013 & 72,615 & 103,904 & 147,276 & 193,332 \\
\hline
\end{tabular}

are based on the assumption that the age- and sex-specific pattern of these fractures is similar to that observed in Malmo [20]. As already noted, this assumption has been shown to be safe in studies reported from many countries [13, 21-23, 29-31], despite differences in incidence between these countries [26]. This commonality of pattern is supported by register studies, which indicate that in those regions where hip fracture rates are high, so too is the risk of forearm fracture and spine fractures (requiring hospital admission) [32, 33].

The incidence of hip fracture was used to create a FRAX tool to compute the 10-year probabilities of hip and major osteoporotic fracture in Uzbekistan. Ten-year probabilities were marginally higher than in the neighbouring countries of Kazakhstan and Kyrgyzstan. Other neighbouring countries are Tajikistan, Afghanistan and Turkmenistan but no FRAX models are available to make comparisons.

The widespread availability of FRAX has resulted in its adoption in many practice guidelines worldwide [8]. The fracture probability equivalent to a woman with a prior fracture has been used as an intervention threshold in more than 30 countries. If the same threshold were applied to Uzbekistan, then intervention would be recommended with a probability

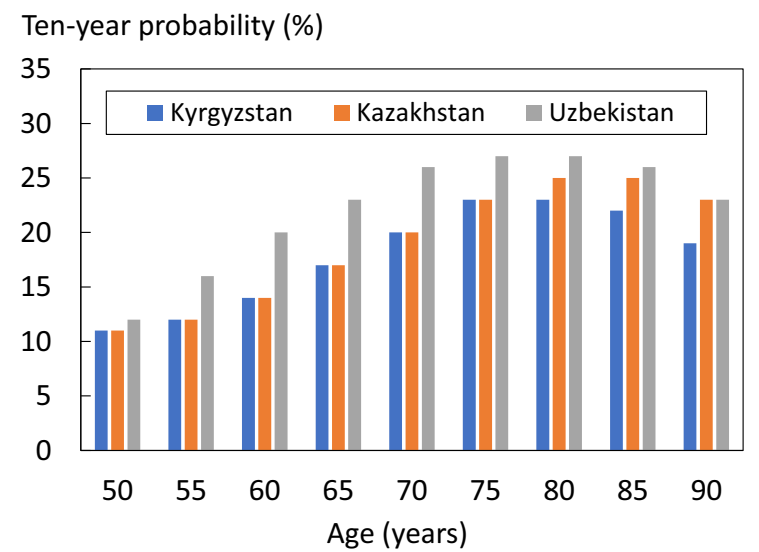

Table 3 Lifetime probability of hip fracture in the Uzbek population from the age of 50 years compared with selected countries

\begin{tabular}{llc}
\hline \multirow{2}{*}{ Country } & \multicolumn{2}{l}{ Lifetime risk at 50 years \% } \\
\cline { 2 - 3 } & Women & Men \\
\hline Sweden & 25.6 & 11.0 \\
Denmark & 23.0 & 11.3 \\
France & 19.3 & 5.9 \\
China (Hong Kong) & 17.7 & 7.6 \\
USA (Caucasian) & 16.1 & 7.5 \\
Turkey & 15.9 & 3.6 \\
Canada & 15.5 & 5.8 \\
Greece & 15.4 & 6.8 \\
Uzbekistan & 14.7 & 8.7 \\
UK & 14.4 & 5.0 \\
Portugal & 13.7 & 4.8 \\
Finland & 12.9 & 6.0 \\
Kazakhstan & 12.6 & 6.0 \\
Spain & 12.6 & 4.2 \\
Kyrgyzstan & 11.7 & 6.4 \\
Bulgaria & 11.2 & 4.4 \\
Hungary & 10.8 & 4.2 \\
Mexico & 10.6 & 5.0 \\
Poland & 10.1 & 4.2 \\
Moldova & 9.3 & 5.7 \\
Russia & 7.7 & 3.8 \\
Romania & 7.0 & 5.6 \\
Ukraine & 5.6 & \\
\hline & & \\
\hline & &
\end{tabular}

${ }^{\text {a }}$ Present study

of a major fracture that varied between 12 and $27 \%$ depending on age. The impact of such thresholds or alternative thresholds will require further study.

There are a number of additional limitations to this study. These include the relatively small sample size and, therefore,

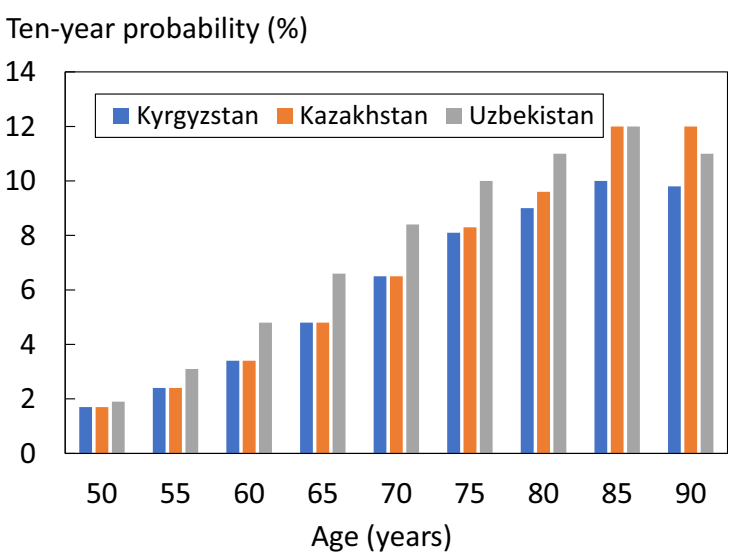

Fig. 2 Ten-year probability of a major osteoporotic fracture (left hand panel) and hip fracture (right) in women with a prior fracture by age from Kyrgyzstan, Kazakhstan and Uzbekistan. Body mass index set to $25 \mathrm{~kg} / \mathrm{m}^{2}$ 
wide confidence intervals from which to compute fracture incidence and the difficulty in case verification. With regard to fracture incidence, we examined less than $1 \%$ of the Uzbek population from a single district. Thus, the extrapolation of this regional estimate to the entire country is an assumption that we were unable to test. In addition to large variations in fracture rates around the world, fracture rates may vary within countries. In addition to ethnic-specific differences [34], up to two-fold differences in hip fracture incidence have been reported using common methodology with the higher rates in urban communities including Croatia [35], Switzerland [36], Norway [37], Argentina [38] and Turkey [39]. A major limitation relates to uncertainties regarding the catchment population. Three estimates for the catchment population is unprecedented in our experience. The highest and lowest numerical estimates would have provided incidence estimates for hip fracture that were the lowest and highest, respectively, world-wide. Their exclusion seems reasonable but does not validate the estimate that we used. If the catchment population were underestimated, this would give rise to a systematic overestimate of fracture probabilities both for hip fracture and major osteoporotic fracture, and vice versa. It is relevant, however, that, accuracy errors have little impact on the rank order with which the FRAX tool categorizes risk within a given population $[12,40]$ but they do change the absolute number generated and thus have implications where treatment guidelines are based on cost-effectiveness or the economic burden of disease.

In summary, a FRAX model has been created for the Republic of Uzbekistan that based on a regional populationbased estimate of the incidence of hip fracture. The model should enhance accuracy of determining fracture probability among the Uzbek population and help to guide decisions about treatment.

\begin{abstract}
Acknowledgements The EVA project was supported by the International Osteoporosis Foundation (Epidemiology and quality of life working group). Servier, however, is acknowledged in helping with organization of the EVA project; 'Epidemiology of osteoporotic fractures in Eurasian counties' study (EVA or ЭBA, in Russian), of which this paper is one of the outcomes. The authors thank Dr A Alimov, Director of the Uzbekistan Republican Medical Center for Endocrinology, and Dr Anvar Khusanov, Head of the Department of Health Care, Namangan Region of Uzbekistan, for their help in organizing the research.
\end{abstract}

Funding information The project did not receive specific funding.

\section{Compliance with ethical standards}

All procedures performed in studies involving human participants were conducted in accordance with the ethical standards of the institutional and national research committee and with the 1964 Helsinki Declaration and its later amendments or compatible ethical standards.

Conflict of interest O Lesnyak, S Ismailov, M Shakirova, N Alikhanova, A Zakroyeva, L Abboskhujaeva, H Johansson, NC
Harvey, E McCloskey and JA Kanis declare that they have no competing interests in relation to this paper. H Johansson, NC Harvey, E McCloskey and JA Kanis are the architects of FRAX in which they have no financial interest.

Open Access This article is licensed under a Creative Commons Attribution 4.0 International License, which permits use, sharing, adaptation, distribution and reproduction in any medium or format, as long as you give appropriate credit to the original author(s) and the source, provide a link to the Creative Commons licence, and indicate if changes were made. The images or other third party material in this article are included in the article's Creative Commons licence, unless indicated otherwise in a credit line to the material. If material is not included in the article's Creative Commons licence and your intended use is not permitted by statutory regulation or exceeds the permitted use, you will need to obtain permission directly from the copyright holder. To view a copy of this licence, visit http://creativecommons.org/licenses/by/4.0/.

\section{References}

1. Hernlund E, Svedbom A, Ivergård M, Compston J, Cooper C, Stenmark J, McCloskey EV, Jönsson B, Kanis JA (2013) Osteoporosis in the European Union: medical management, epidemiology and economic burden. A report prepared in collaboration with the International Osteoporosis Foundation (IOF) and the European Federation of Pharmaceutical Industry Associations (EFPIA). Arch Osteoporos 8:136

2. Johnell O, Kanis JA (2006) An estimate of the worldwide prevalence and disability associated with osteoporotic fractures. Osteoporos Int 17:1726-1733

3. Borgström F, Karlsson L, Ortsäter G, Norton N, Halbout P, Cooper C, McCloskey EV, Harvey NC, Javaid K, Kanis JA for the International Osteoporosis Foundation (2020) Fragility fractures in Europe: burden, management and opportunities. Arch Osteoporos 15: 59. https://doi.org/10.1007/s11657-020-0706-y

4. Kanis JA, Cooper C, Rizzoli R, Reginster J-Y, Scientific Advisory Board of the European Society for Clinical and Economic Aspects of Osteoporosis (ESCEO) and the Committees of Scientific Advisors and National Societies of the International Osteoporosis Foundation (IOF) (2019) European guidance for the diagnosis and management of osteoporosis in postmenopausal women. Osteoporos Int 30:3-44

5. Kanis JA on behalf of the World Health Organization Scientific Group (2008) Assessment of osteoporosis at the primary healthcare level Technical Report. WHO Collaborating Centre, University of Sheffield, UK. Available at . http://www.shef.ac.uk/FRAX/pdfs/ WHO_Technical_Report.pdf. Accessed 26 Feb 2020

6. Kanis JA, Johnell O, Oden A, Johansson H, McCloskey E (2008) FRAX $^{\mathrm{TM}}$ and the assessment of fracture probability in men and women from the UK. Osteoporos Int 19:385-397

7. Odén A, McCloskey EV, Kanis JA, Harvey NC, Johansson H (2015) Burden of high fracture probability worldwide: secular increases 2010-2040. Osteoporos Int 26:2243-2248

8. Kanis JA, Harvey NC, Cyrus Cooper C, Johansson H, Odén A, McCloskey EV, the Advisory Board of the National Osteoporosis Guideline Group (2016) A systematic review of intervention thresholds based on FRAX. A report prepared for the National Osteoporosis Guideline Group and the International Osteoporosis Foundation. Arch Osteoporos 11:25

9. Kanis JA, Johansson H, Harvey NC, McCloskey EV (2018) A brief history of FRAX. Arch Osteoporos 13:118. https://doi.org/10.1007/ s11657-018-0510-0 
10. Lesnyak O, Ershova O, Belova K, Gladkova E, Sinitsina O, Ganert O, Romanova M, Khodirev V, Johansson H, McCloskey E, Kanis JA (2012) Epidemiology of fracture in the Russian Federation and the development of a FRAX model. Arch Osteoporos 7:67-73. https://doi.org/10.1007/s11657-012-0082-3

11. Lesnyak O, Sahakyan S, Zakroyeva A, Bilezikian JP, Hutchings N, Galstyan R, Lebedev A, Johansson H, Harvey NC, McCloskey E, Kanis JA (2017) Epidemiology of fractures in Armenia: development of a country-specific FRAX model and comparison to its surrogate. Arch Osteoporos 12(1):98. https://doi.org/10.1007/ s11657-017-0392-6

12. Ramanau H, Chernyanin I, Rudenka E, Lesnyak O, Zakroyeva A, Bilezikian JP, Johansson H, Harvey NC, McCloskey EV, Kanis JA (2018) Epidemiology of hip fracture in Belarus: development of a country-specific FRAX model and its comparison to neighbouring country models. Arch Osteoporos 13:42. https://doi.org/10.1007/ s11657-018-0454-4

13. Zakroyeva A, Lesnyak O, Cazac V, Groppa L, Russu E, Chislari L, Rotaru L, Johansson H, Harvey NC, McCloskey E, Kanis JA (2020) Epidemiology of osteoporotic fracture in Moldova and development of a country specific FRAX model. Arch Osteoporos 15: 13. https://doi.org/10.1007/s11657-019-0669-z

14. Issayeva $\mathrm{S}$, Lesnyak $\mathrm{O}$, Zakroyeva $\mathrm{A}$, Issayeva $\mathrm{B}$, Dilmanova $\mathrm{D}$, Johansson H, Harvey NC, McCloskey E, Kanis JA (2020) Epidemiology of osteoporotic fractures in the Republic of Kazakhstan and the development of country specific FRAX model. Arch Osteoporos 15(1):30. https://doi.org/10.1007/s11657-0200701-3

15. Lesnyak O, Zakroyeva A, Lobanchenko O, Johansson H, Liu E, Lorentzon M, Harvey NC, McCloskey E, Kanis JA (2020) A surrogate FRAX model for the Kyrgyz Republic. Arch Osteoporos 15: 68. https://doi.org/10.1007/s11657-020-00743-2

16. United Nations (2019) Department of Economic and Social Affairs/ population division. World Population Prospects https:// populationunorg/wpp/Download/Standard/Population/ Accessed 11 Jan 2020

17. Republic Uzbekistan State Department of Statistics (2018). www. stat.uz Accessed 27 Dec 2019

18. The state committee of the Republic of Uzbekistan on statistics (2020) https://stat.uz/en/181-ofytsyalnaia-statystyka-en/6383demography Accessed 19 March 2020

19. International Osteoporosis Foundation (2011) The Eastern European \& Central Asian Regional Audit. Epidemiology, costs \& burden of osteoporosis in 2010. Naturaprint, France. Available at https://www.iofbonehealth.org/sites/default/files/PDFs/Audit\% 20Eastern\%20Europe_Central\%20Asia/Eastern_European Central_Asian_Audit_2010.pdf. Accessed 11 Dec 2019

20. United Nations (2017) Department of Economic and Social Affairs/ population division. World Population Prospects https:// wwwworldometersinfo/world-population/uzbekistan-population/ Accessed 12 May 2020

21. Kanis JA, Oden A, Johnell O, Jonsson B, de Laet C, Dawson A (2001) The burden of osteoporotic fractures: a method for setting intervention thresholds. Osteoporos Int 12:417-427

22. Siggeirsdottir K, Aspelund T, Johansson H, Gudmundsson EF, Mogensen B, Jonsson BY, Gudnason V, McCloskey E, Oden A, Sigurdsson G, Kanis JA (2014) The incidence of a first major osteoporotic fracture in Iceland and implications for FRAX. Osteoporos Int 25:2445-2451

23. Lam A, LeslieWD LLM, Yogendran M, Morin SN, Majumdar SR (2014) Major osteoporotic to hip fracture ratios in Canadian men and women with Swedish comparisons: a population-based analysis. J Bone Miner Res 29:1067-1073
24. World Health Organization (2018) Health statistics and information systems: http://www.who.int/healthinfo/statistics/mortality_ rawdata/en/ Accessed 17th June 2019

25. Kanis JA, Johnell O, De Laet C, Jonsson B, Oden A, Ogelsby AK (2002) International variations in hip fracture probabilities: implications for risk assessment. J Bone Miner Res 17:1237-1244

26. Kanis JA, Odén A, McCloskey EV, Johansson H, Wahl D, Cyrus Cooper $\mathrm{C}$ on behalf of the IOF Working Group on Epidemiology and Quality of Life (2012) A systematic review of hip fracture incidence and probability of fracture worldwide. Osteoporos Int 23:2239-2256

27. Povoroznyuk VV, Grygorieva NV, Kanis JA, McCloskey EV, Johansson H, Harvey NC, Korzh MO, Strafun SS, Vaida VM, Klymovytsky FV, Vlasenko RO, Forosenko VS (2017) Epidemiology of hip fracture and the development of FRAX in Ukraine. Arch Osteoporos 12:53

28. Cooper C, Cole ZA, Holroyd CR, Earl SC, Harvey NC, LJ DEMM, Cummings SR, Kanis JA, the IOF CSA Working Group on Fracture Epidemiology (2011) Secular trends in the incidence of hip and other osteoporotic fractures. Osteoporos Int 22:1277-1288

29. Melton LJ, Crowson CS, O'Fallon WM (1999) Fracture incidence in Olmsted County, Minnesota: comparison of urban and with rural rates and changes in urban rates over time. Osteoporos Int 9:29-37

30. Singer BR, McLauchlan CJ, Robinson CM, Christie J (1998) Epidemiology of fracture in 15.000 adults. The influence of age and gender. J Bone Joint Surg 80B:234-238

31. Sanders KM, Seeman E, Ugoni AM, Pasco JA, Martin TJ, Skoric B, Nicholson GC, Kotowicz MA (1999) Age- and gender specific rate of fractures in Australia: a population-based study. Osteoporos Int 10(2):40-47

32. Johnell O, Gullberg B, Kanis JA (1997) The hospital burden of vertebral fracture in Europe: a study of national register sources. Osteoporos Int 7:138-144

33. Melton LJ (1995) Epidemiology of fractures. In: Riggs BL, Melton LJ (eds) Osteoporosis: etiology, diagnosis and management, 2nd edn. Lippincott-Raven, Philadelphia, pp 225-227

34. Cauley JA, Chalhoub D, Kassem AM, el-H FG (2014) Geographic and ethnic disparities in osteoporotic fractures. Nat Rev Endocrinol $10: 338-351$

35. Karacić TP, Kopjar B (2009) Hip fracture incidence in Croatia in patients aged 65 years and more. Lijec Vjesn 131:9-13

36. Lippuner K, Johansson H, Kanis JA, Rizzoli R (2010) FRAX assessment of osteoporotic fracture probability in Switzerland. Osteoporos Int 21:381-389

37. Emaus N, Olsen LR, Ahmed LA, Balteskard L, Jacobsen BK, Magnus T, Ytterstad B (2011) Hip fractures in a city in Northern Norway over 15 years: time trends, seasonal variation and mortality: the Harstad Injury Prevention Study. Osteoporos Int 22:26032610

38. Morosano M, Masoni A, Sánchez A (2005) Incidence of hip fractures in the city of Rosario. Argentina: Osteoporos Int 16:13391344

39. Elffors L, Allander E, Kanis JA, Gullberg B, Johnell O, Dequeker J, Dilzen G, Gennari C, Lopez-Vaz AA, Lyritis G, Mazzuoli GF, Miravet L, Passeri M, Perez Cano R, Rapado A, Ribot C (1994) The variable incidence of hip fracture in Southern Europe. The MEDOS Study. Osteoporos Int 4:253-263

40. Kanis JA, Johansson H, Oden A, Dawson-Hughes B, Melton LJ 3rd, McCloskey EV (2010) The effects of a FRAX® revision for the USA. Osteoporos Int 21:35-40

Publisher's note Springer Nature remains neutral with regard to jurisdictional claims in published maps and institutional affiliations. 